\title{
Regulation of lipid droplet-associated proteins following growth hormone administration and feed restriction in lactating Holstein cows
}

\author{
M. P. Faylon, D. E. Koltes, and D. M. Spurlock ${ }^{1}$ \\ Department of Animal Science, lowa State University, Ames 50011
}

\section{ABSTRACT}

Lipid metabolism plays a crucial role in the adaptation of dairy cows to periods of energy insufficiency. The objective of the current study was to determine if lipolytic proteins are consistently regulated when energy mobilization is stimulated by different factors. We evaluated 2 models of altered energy balance in midlactation Holstein cows, including feed restriction (FR) and administration of bovine growth hormone $(\mathrm{GH})$, by quantifying the abundance and (or) phosphorylation of hormone-sensitive lipase (HSL), perilipin (PLIN), and adipose triglyceride lipase (ATGL). For GH administration, adipose tissue and blood samples were collected 4 $\mathrm{d}$ before and 3 and $7 \mathrm{~d}$ after administration of GH (n $=20$ cows). Similarly, adipose and blood samples were obtained $6 \mathrm{~d}$ before and 1 and $4 \mathrm{~d}$ after initiation of FR $(\mathrm{n}=18$ cows $)$. Estimated net energy balance decreased and nonesterified fatty acid concentration increased in both experimental models. Decreased ATGL and PLIN protein abundance was observed with GH administration and FR. Additionally, the abundance of phosphorylated $\mathrm{HSL}_{\mathrm{Ser} 565}$ decreased in both models. Decreased abundance of phosphorylated PLIN was observed with GH administration, but not FR. Decreased ATGL protein abundance appears to be a consistent response to energy insufficiency in lactating cows, as this response was also described with negative energy balance at the onset of lactation. In contrast, the abundance of PLIN protein and phosphorylation of HSL using antibodies targeting serine residue 565 of $\mathrm{HSL}\left(\mathrm{HSL}_{\mathrm{Ser} 565}\right)$ were altered in the current research, but not at the onset of lactation. Our findings demonstrate that lipolysis is altered through the regulation of multiple proteins, and that this regulation differs according to physiological state in lactating cows.

Key words: adipose triglyceride lipase, perilipin, hormone-sensitive lipase, energy balance

Received October 4, 2013.

Accepted February 5, 2014.

${ }^{1}$ Corresponding author: moodyd@iastate.edu

\section{INTRODUCTION}

Lipid metabolism is critical to the balance between production and fitness traits that contribute to the survival and reproduction rates of lactating dairy cattle. During times of energy insufficiency, lipid metabolism favors lipolysis and body fat energy reserves in the form of triacylglycerides are mobilized to support lactation. Proper regulation and coordination of lipolysis are essential to ensure the availability of adequate energy for lactation, maintenance, and reproduction.

Lipid mobilization is a highly conserved process involving multiple enzymes that are regulated at the posttranslational level (Watt and Steinberg, 2008; Lampidonis et al., 2011). For many years, hormone-sensitive lipase (HSL) was believed to be the rate-limiting enzyme of lipolysis (Duncan et al., 2007). The cyclic AMP-dependent activation of protein kinase A (PKA) leads to phosphorylation of HSL, which in turn allows the translocation of HSL to the lipid droplet (LD) and enhances enzyme activity (Haemmerle et al., 2002). Perilipin (PLIN) is a protein found on the surface of LD and is also a target of PKA-mediated phosphorylation in 3T3-L1 adipocytes (Moore et al., 2005; Brasaemle, 2010). Under basal conditions, PLIN protects the LD from HSL-mediated lipolysis. Once phosphorylated, PLIN undergoes a conformational change, allowing HSL access to the LD and its lipid substrate (Miyoshi et al., 2006). More recently, the characterization of HSL-deficient mice provided compelling evidence that revised the concept that HSL is uniquely responsible for the hydrolysis of triacylglycerols and diacylglycerols of stored fat (Rydén et al., 2007). Adipose triglyceride lipase (ATGL) is predominantly expressed in mouse adipose tissue and exhibits high substrate specificity for triacylglycerides (Villena et al., 2004; Zimmermann et al., 2004). Adipose triglyceride lipase becomes activated by another LD-associated protein, comparative gene identity protein 58 (CGI-58), following its dissociation from and upon phosphorylation of PLIN (Schweiger et al., 2006; Granneman et al., 2007). It has been demonstrated in human and animal models, such as pigs and mice, that ATGL abundance increases in response to glucocorticoids and caloric restriction, 
suggesting that its protein abundance becomes elevated with an increasing demand for lipid mobilization due to metabolic or pharmacologic stimuli (Deiuliis et al., 2008). However, little is known about the regulation of ATGL or other lipolytic proteins in dairy cattle.

The underlying hypothesis of the current research is that the abundance and phosphorylation of HSL, PLIN, and ATGL are altered with changing energy balance to facilitate coordinated metabolic changes necessary for lactation. We previously described changes in lipolytic proteins relative to changes in energy balance that occur throughout a lactation cycle (Koltes and Spurlock, 2011). The objective of the current study was to determine if lipolytic proteins are consistently regulated when energy mobilization is stimulated by different pathways. To accomplish this objective, we evaluated 2 additional models of altered energy balance in mid-lactation Holstein cows: feed restriction and administration of bovine growth hormone. We then quantified the abundance or phosphorylation or both of HSL, PLIN, and ATGL in response to these models of altered energy balance.

\section{MATERIALS AND METHODS}

All animal experiments in this study were performed under a protocol approved by the Iowa State University Institutional Animal Care and Use Committee (Ames).

\section{Animals}

The animals and experimental treatments used in this research have been described previously (Koltes and Spurlock, 2011, 2012). Briefly, cows were trained and acclimated to the Calan Broadbent feeding system (American Calan Inc., Northwood, $\mathrm{NH}$ ) for 4 to $6 \mathrm{~d}$ before initiation of each experiment. Cows were fed ad libitum and received a basal diet formulated using NRC (2001) recommendations to meet or exceed the nutritional requirements of lactating cows. Individual feed intake was measured on a daily basis. Dry matter and net energy content $\left(\mathrm{NE}_{\mathrm{L}}\right)$ were determined from TMR samples. Body weights were recorded weekly, following milking in the morning. Milk yield was recorded at each milking, and the percentage of fat, protein, and lactose were determined from weekly samples collected at a morning milking. Net energy balance was estimated as the difference between $\mathrm{NE}_{\mathrm{L}}$ consumed and utilized for milk production and maintenance (NRC, 2001).

Three adipose tissue biopsies were taken from each cow. During each biopsy, four 1-g samples of subcutaneous adipose tissue were collected from the tailhead region using a minimally invasive procedure as previously described (Koltes and Spurlock, 2011, 2012). The adipose tissue samples were immediately frozen in liquid nitrogen and stored at $-80^{\circ} \mathrm{C}$ until protein analysis. Samples were obtained from alternating sides of the cow, and the third biopsy sample was obtained approximately $5 \mathrm{~cm}$ anterior to the previous biopsy location.

To confirm that the experimental treatments stimulated lipolysis, blood samples were obtained via jugular venipuncture following each biopsy for measurement of NEFA. The concentration of NEFA was determined using a commercially available kit following the manufacturer's protocol (Randox Laboratories Ltd., Crumlin, $\mathrm{UK})$.

Feed Restriction. Eighteen multiparous Holstein cows between 175 and $210 \mathrm{~d}$ postpartum were used in 2 replicates ( $\mathrm{n}=9$ for both), which were done 1 mo apart. Baseline feed intake measurements were obtained for $5 \mathrm{~d}$ before initiation of treatment. To simulate energy insufficiency similar to that of the transition period, feed intake was restricted to achieve a targeted energy balance level of $-10 \mathrm{Mcal}$, with a maximum restriction of $50 \%$ of the baseline feed intake. On the third day of feed restriction (FR), the quantity of feed provided to each cow was readjusted to account for changes in milk production. Cows were fed 4 times daily throughout the FR period. Adipose tissue samples were collected $6 \mathrm{~d}$ before (control), and 1 and $4 \mathrm{~d}$ after initiation of FR. Likewise, blood samples were taken immediately following each biopsy for analysis of NEFA, as previously described. In this experimental design, biopsy 1 served as the control for biopsies 2 and 3, within cow.

Growth Hormone Administration. Twenty multiparous Holstein cows between 175 and 210 d postpartum were evaluated in 2 replicates, separated in time by $2 \mathrm{~d}$. As with the previous experiment, baseline feed intake was measured for $5 \mathrm{~d}$ before administration of growth hormone $(\mathbf{G H})$. Bovine GH was administered as a single dose of Posilac (500 $\mathrm{mg}$ of sometribove zinc; Elanco Animal Health, Greenfield, IN), given via a subcutaneous injection in the neck. Adipose tissue was sampled $4 \mathrm{~d}$ before (control), and 3 and $7 \mathrm{~d}$ after administration of the GH. Similarly, blood samples were collected immediately following each biopsy for NEFA analysis. As with the FR treatment, biopsy 1 served as the control for biopsies 2 and 3, within cow.

\section{Semiquantitative Western Blotting}

Total abundance of HSL, ATGL, and PLIN was determined by semiquantitative Western blotting. Additionally, phosphorylation of HSL using antibodies targeting serine residues 563 and 565 (HSL $_{\text {Ser563 }}$ and HSL $\left._{\text {Ser565 }}\right)$ was investigated because these sites are targeted by PKA (HSL $\mathrm{Her563}$ ) and adenosine monophosphate-activated protein kinase $\left(\mathbf{A M P K} ; \mathrm{HSL}_{\mathrm{Ser} 565}\right)$ to 
stimulate and inhibit HSL activity, respectively, in both human skeletal muscle and adipose tissue (Watt et al., 2006). These antibodies are predicted to target serine residues 552 and 554 of the bovine HSL amino acid sequence (P16386), but will be referred to as $\mathrm{HSL}_{\mathrm{Ser} 563}$ and $\mathrm{HSL}_{\mathrm{Ser} 565}$ for consistency with the literature. Phosphorylated PLIN (PPLIN) was detected using the total PLIN antibody, but the phosphorylated form of the protein was revealed by size separation during gel electrophoresis. The PLIN antibody is specific for bovines, and whereas the rest of the primary antibodies used in this study were produced based on human sequence, BLAST searches (http://blast.ncbi.nlm.nih.gov/Blast. cgi) revealed high sequence homology $(91 \%)$ and identity $(92 \%)$ with the bovine sequence. The protocol for the extraction and preparation of proteins from adipose tissue for use in Western blotting has been previously described (Elkins and Spurlock, 2009). Bicinchoninic assay (BCA; Pierce Protein Research Products, Rockford, IL) was performed to determine protein concentrations, which were used to standardize the quantity of total protein loaded onto each gel. In addition, arbitrarily chosen samples were loaded onto lanes flanking the samples from each cow to serve as standards for normalization across gels. Proteins were separated overnight in $10 \%$ (for detection of PPLIN) or $8 \%$ (for detection of all other proteins) SDS-polyacrylamide gels and transferred to polyvinylidine fluoride membranes. Following transfer, membranes were blocked with 5\% milk in Tris-buffered saline-Tween 20 (TBS-T) for at least $1 \mathrm{~h}$. Blots were incubated with the primary antibodies (Table 1), followed by incubation with antirabbit IgG horseradish peroxidase-linked secondary antibody (GE Healthcare, Pittsburgh, PA). Protein bands were detected with the ECL Plus Western Detection Kit (Amersham Biosciences Inc., Pittsburgh, PA) using an Alpha Innotech Imager (FluorChem FC2; Cell Biosciences Inc., Santa Clara, CA) and quantified using TotalLab software for 1D gel analysis (TL100, v2009; TotalLab Ltd., Newcastle upon Tyne, UK). Data for each sample were normalized using the average value of the 2 standard lanes flanking the samples from each cow. Protein abundance was expressed in relative units for subsequent statistical analyses.

\section{Data Analysis}

All data were analyzed as a completely randomized design using PROC MIXED of SAS (SAS Institute, 1999). The model included biopsy day as a fixed effect, with cow and replicate as random factors. When the main effect of biopsy day was significant $(P<0.05)$, differences among the means were determined using PROC PDIFF. The interaction effect between biopsy

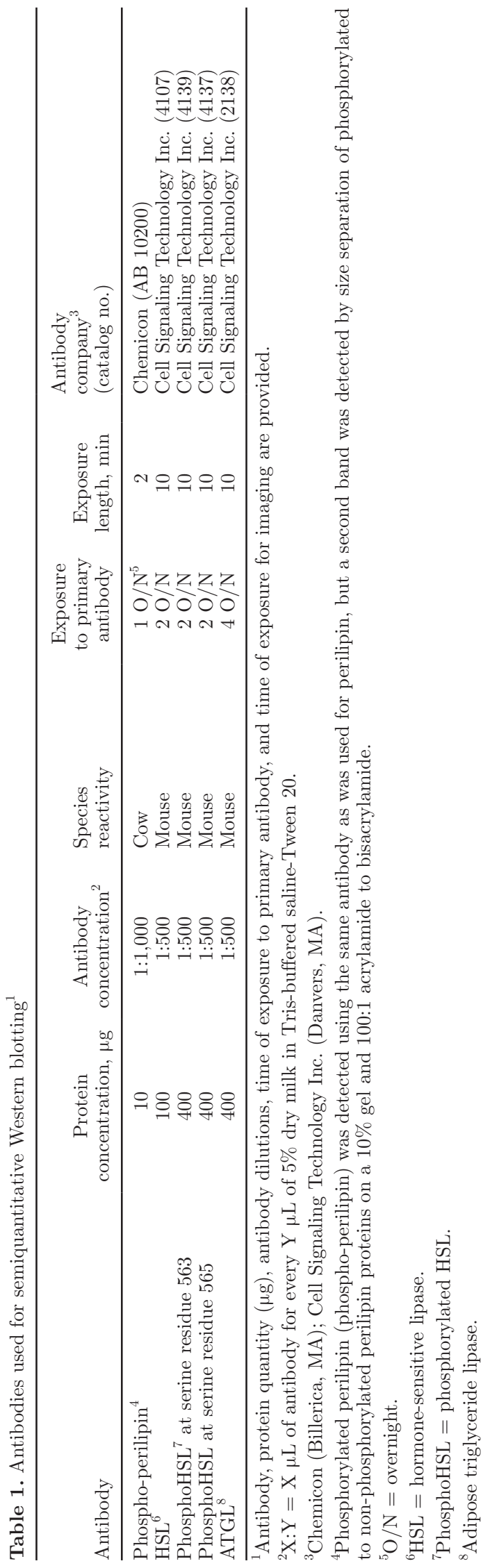

Journal of Dairy Science Vol. 97 No. 5, 2014 
day and replicate was initially tested but was nonsignificant and subsequently removed from final analyses. All values are presented as means \pm standard error, with statistical significance set at $P<0.05$.

\section{RESULTS}

\section{Milk Production, Energy Balance, and NEFA Concentration}

Changes in milk production, energy balance, and circulating NEFA with GH and FR have been described previously (Koltes and Spurlock, 2012). Briefly, production data collected during the FR experiment showed a steady decrease in milk yield starting from the initiation of FR. In contrast, milk production of cows administered GH increased throughout the 7-d experiment. Energy balance of the feed-restricted cows decreased upon treatment, and was negative throughout the $4 \mathrm{~d}$ of restriction. This was accompanied by an increase in plasma NEFA concentration on d 1 and 4, relative to the control. Energy balance also decreased with the administration of GH, but average energy balance across all cows remained slightly positive throughout the experimental period. Increased plasma NEFA concentration confirmed elevated lipid mobilization in GH-treated cows.

\section{Lipolytic Proteins}

Protein abundance of ATGL decreased following FR $(P=0.03$; Figure $1 \mathrm{~A})$. The abundance of phosphorylated $\mathrm{HSL}_{\text {Ser565 }}$ also decreased $(P<0.001$; Figure

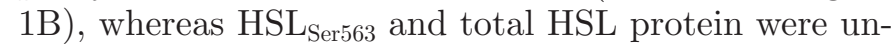
changed $(P=0.57$ and $P=0.41$, respectively). Protein abundance of total PLIN decreased $(P=0.034)$, but no significant change in PPLIN was observed $(P=0.13$; Figure 1C) following FR.

Similarly, treatment with GH was also associated with a decline in the abundance of ATGL protein $(P<0.001$; Figure $2 \mathrm{~A})$ and $\mathrm{PHSL}_{\text {Ser565 }}(P=0.02$; Figure 2B). The effect of treatment day on HSL and $\mathrm{PHSL}_{\text {Ser563 }}(P=0.26$ and $P=0.49$, respectively $)$ were not significant (Figure 2A and B). Total PLIN concentration decreased after $\mathrm{GH}$ treatment $(P=0.004)$, as did PPLIN concentration $(P=0.04$; Figure $2 \mathrm{C})$.

\section{DISCUSSION}

Dairy cattle typically undergo extensive remodeling of adipose tissue throughout a lactation cycle. Appropriate regulation of lipolysis and lipogenesis is essential for the maintenance of energy supplies for both lactation and fitness traits. Although several proteins have
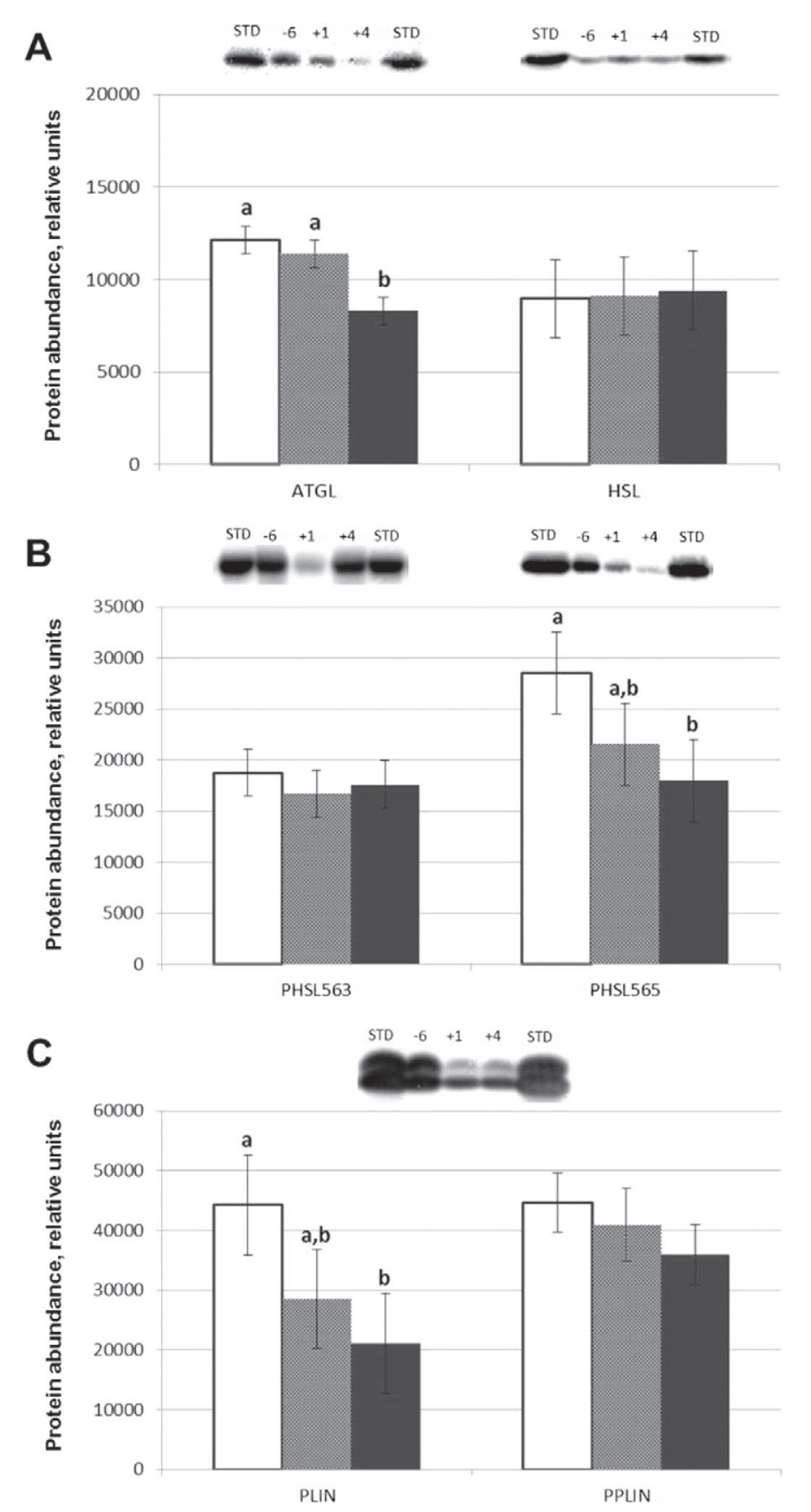

Figure 1. Abundance of lipid droplet-associated proteins in subcutaneous adipose tissue in response to feed restriction. Adipose tissue samples were obtained $6 \mathrm{~d}$ (solid white) before, and 1 (gray) and $4 \mathrm{~d}$ (solid black) after restricted feeding. Protein abundance of (A) adipose triglyceride lipase (ATGL) and hormone-sensitive lipase (HSL), (B) phosphorylated HSL at serine residues 563 and 565 (PHSL563 and PHSL565, respectively), and (C) perilipin (PLIN) and phosphorylated PLIN (PPLIN) was determined by semiquantitative Western blotting and expressed in relative units per quantity of total protein (10-400 $\mu \mathrm{g}$ ) after normalization across gels to a common standard (STD). Each inset shows a representative Western blot. For PLIN (C), the upper band was quantified as PPLIN, and the lower band as PLIN. Given are the means \pm SEM. Different letters (a and b) indicate differences among means $(P<0.05)$. 

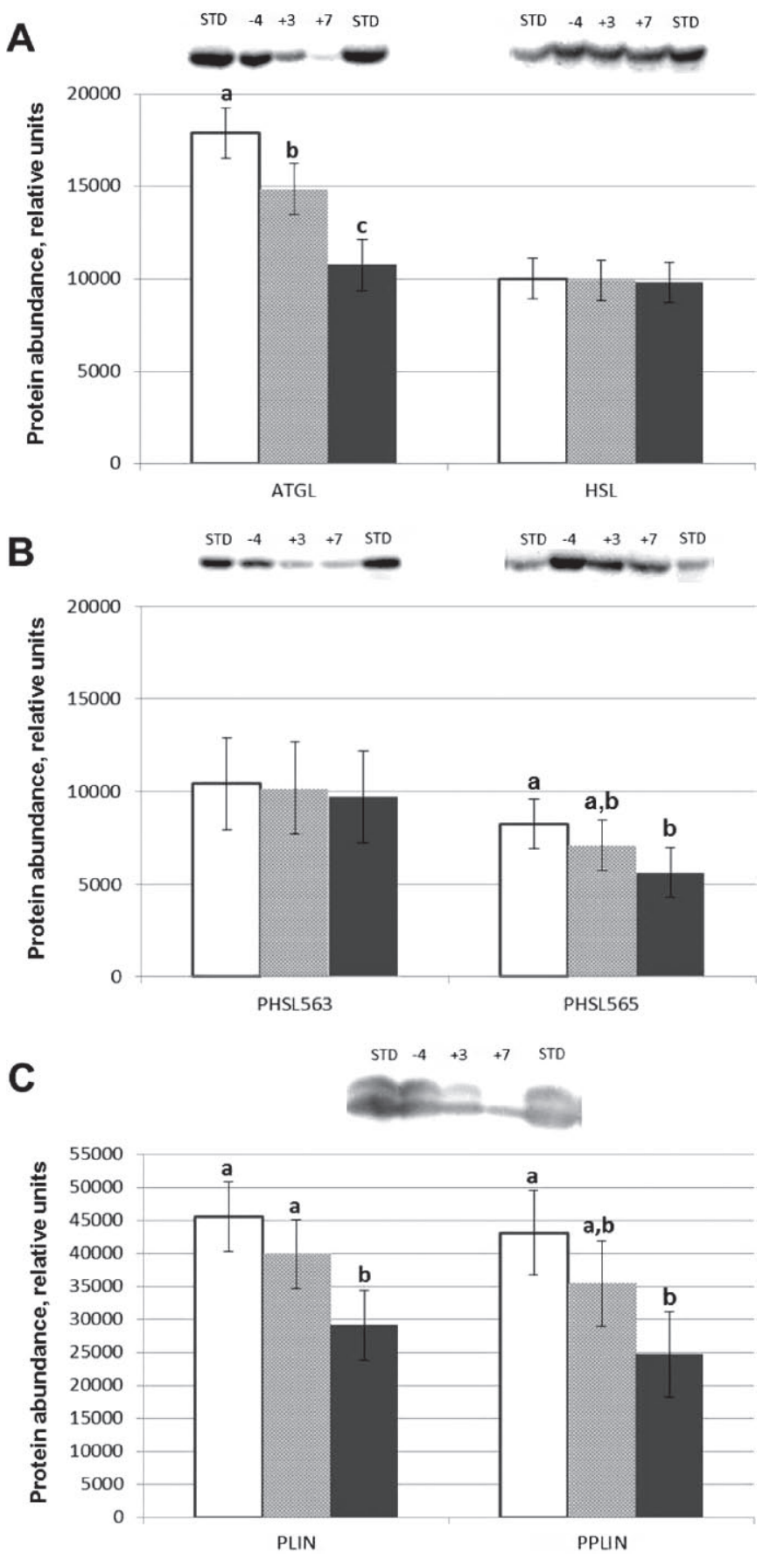

Figure 2. Abundance of lipid droplet-associated proteins in subcutaneous adipose tissue in response to growth hormone administration determined via semiquantitative Western blotting. Adipose tissue samples were obtained $4 \mathrm{~d}$ (solid white) before and 3 (gray) and $7 \mathrm{~d}$ (solid black) after treatment. Protein abundance of (A) adipose triglyceride lipase (ATGL) and hormone-sensitive lipase (HSL), (B) phosphorylated HSL at serine residues 563 and 565 (PHSL563 and PHSL565, respectively), and (C) perilipin (PLIN) and phosphorylated PLIN (PPLIN) is expressed in relative units per quantity of total protein $(10-400 \mu \mathrm{g})$ after normalization across gels to a common standard (STD). Each inset shows a representative Western blot. For perilipin (C), the upper and lower bands represent PPLIN and PLIN, respectively. Given are the means \pm SEM. Different letters $(\mathrm{a}-\mathrm{c})$ indicate differences among means $(P<0.05)$. been recognized to participate in lipolysis (Kolditz and Langin, 2010; Contreras and Sordillo, 2011; Lass et al., 2011), the regulation of these proteins in response to changing energy balance, particularly in the dairy cow, is poorly understood. We previously reported that ATGL, HSL, and PLIN are dynamically regulated in subcutaneous adipose tissue throughout the lactation cycle of multiparous Holstein cows (Koltes and Spurlock, 2011). The objective of the present study was to evaluate the regulation of these lipolytic proteins when lipolysis is stimulated by physiological factors including FR and administration of GH during mid lactation. A summary of the response of HSL, ATGL, and PLIN to the 3 experimental models evaluated by our group (lactation cycle, FR, and GH administration) is provided in Table 2.

The most consistent result across experimental models is the decrease in abundance of ATGL with increasing lipolytic activity. This result is unexpected because ATGL protein abundance increases with enhanced lipolytic activity during fasting in pigs, rodents, and humans (Caimari et al., 2008; Kershaw et al., 2006; Deiuliis et al., 2008; Nielsen et al., 2012). However, our protein data from the transition period (Koltes and Spurlock, 2011) are consistent with ATGL mRNA expression also described for early-lactation cows (Ji et al., 2012). The reason for the discrepancy between results in lactating cows and published results from other species is unclear. To our knowledge, our research is the first to investigate the modulation of ATGL protein in lactating animals. It is currently unknown if the homeorhetic changes associated with lactation, especially in high milk-producing dairy cows, influence the physiological signals regulating ATGL. The abundance of ATGL increased following feeding of a high-fat diet in mice (Gaidhu et al., 2010). This regulation may have occurred to balance the excessive adiposity due to the high-fat diet, and is consistent with the proposed role of ATGL as a regulator of basal lipolysis (Mairal et al., 2006; Rydén et al., 2007). As such, ATGL may be downregulated in our experimental models as an adaptive mechanism to prevent excessive hydrolysis of lipids during periods of energy insufficiency during lactation.

Alternatively, the observed decrease in ATGL protein abundance may reflect a lack of correlation between protein abundance and ATGL activity. Most notably, ATGL is activated by CGI-58 (Yamaguchi et al., 2004; Granneman et al., 2007) and inhibited by the G(0)/G(1) switch gene 2 (Lu et al., 2010). Additionally, localization of ATGL to the LD is influenced by the presence of perilipins (Wang et al., 2011). Therefore, the decreased abundance of ATGL observed in our experimental models may not accurately reflect changes in ATGL activity. The timeline of investigation may 
Table 2. Changes in abundance or phosphorylation of lipolytic proteins in different models of altered energy balance in dairy cows

\begin{tabular}{lccc}
\hline & \multicolumn{3}{c}{ Response $^{2}$} \\
\cline { 2 - 4 } Protein $^{1}$ & Transition $^{3}$ & $\begin{array}{c}\text { Feed } \\
\text { restriction }\end{array}$ & $\begin{array}{c}\text { Growth } \\
\text { hormone }\end{array}$ \\
\hline ATGL & $\downarrow$ & $\downarrow$ & $\downarrow$ \\
HSL & NS & NS & NS \\
PHSL $_{\text {Ser563 }}$ & $\uparrow$ & NS & NS \\
PHSL $_{\text {Ser565 }}$ & NS & $\downarrow$ & $\downarrow$ \\
PLIN $_{\text {PPLIN }}$ & $\uparrow S$ & $\downarrow$ & $\downarrow$ \\
\hline
\end{tabular}

${ }^{1}$ ATGL $=$ adipose triglyceride lipase; HSL = hormone-sensitive lipase

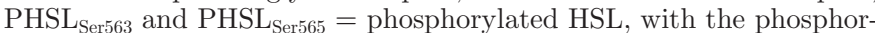
ylation using antibodies targeting serine residues 563 and 565 of HSL, respectively; PLIN $=$ perilipin; PPLIN $=$ phosphorylated PLIN.

${ }^{2} \mathrm{NS}=$ no significant differences among treatments $(P \geq 0.05) ; \downarrow$ or $\uparrow$ indicates a decrease or increase in abundance of protein, respectively.

${ }^{3}$ Data obtained from Koltes and Spurlock (2011).

also affect observed changes in ATGL protein. Yang et al. (2013) proposed that ATGL may play an important regulatory role during long-term stimulation of lipolysis but is less involved in the acute lipolytic response. Our studies investigated ATGL following several days of altered energy balance, whereas prior studies focused largely on changes within a 6- to 8-h period (Kim et al., 2006; Jocken et al., 2007). Differences in the response of ATGL to experimental treatments may reflect differences between acute and chronic regulation of the lipase.

Furthermore, differences in the morphology and composition of adipose tissue have been reported as a result of triglyceride breakdown in response to a change in physiological state. It may be argued that the changes observed in ATGL may have been affected by the probable presence of other cell types in the biopsy sample, which may have diluted and decreased protein abundance. Martin et al. (2009) and Greenberg et al. (1991) reported that HSL and PLIN are predominantly expressed in the adipose tissue, such that variability in the levels of these phosphoproteins may be indicative of any change in the state of the adipose tissue sample. The fact that in the current study, no significant changes in total HSL and PHSL Seer563 $_{\text {were observed suggests that }}$ the variation in ATGL abundance reflects what is happening in adipose tissue during altered energy balance. Moreover, although a significant decrease in PLIN was observed after FR and GH administration, we believe that the time lapse between treatment and biopsy was short enough that major changes in the composition of the samples were unlikely. In a related study, Koltes and Spurlock (2012) found that following FR and GH treatment, mRNA abundance of $60 \mathrm{~S}$ ribosomal protein L32 (RPL32) in cows did not change with sampling day, a possible indication that the proportion of protein from adipose tissue did not differ across biopsy times.

A decline in total PLIN protein abundance was observed following FR and GH administration, but not with stage of lactation (Koltes and Spurlock, 2011). Perilipin regulates lipolysis via multiple mechanisms. It was first described as having a barrier effect, whereby the presence of PLIN on the LD limited access of lipases to their lipid substrate (Garcia et al., 2004). It was subsequently discovered that upon phosphorylation of PLIN by PKA, a conformational change to PLIN occurs that allows the release of CGI-58 for activation of ATGL, and interaction of PLIN with HSL to facilitate lipolysis (Subramanian et al., 2004). Following this latter discovery, a majority of the research has focused more on this important role of PLIN as facilitator of PKA-stimulated lipolysis rather than just as a LD barrier. Our data suggest the abundance of total PLIN is important in the regulation of lipolysis in response to both FR and GH administration during mid lactation, and that this regulation may reflect the potential of PLIN to act as a barrier to lipolysis. Phosphorylation of PLIN and $\mathrm{HSL}_{\text {Ser563 }}$ is accomplished by PKA, and this is a primary mechanism for lipolytic stimulation following catecholamine activation of $\beta$-adrenergic receptors (Anthonsen et al., 1998; Jocken et al., 2007). Increased phosphorylation of PPLIN, HSL $\mathrm{Her563}_{\text {, }}$ and HSL serine residue 660, another PKA targeted site, has been described in cattle with the onset of lactation (Koltes and Spurlock, 2011; Locher et al., 2011). In the current study, FR and GH administration in mid lactation did not alter phosphorylation of PLIN or $\mathrm{HSL}_{\mathrm{Ser} 563}$. Chronic administration of GH is known to stimulate lipolysis in lactating cattle, in part through decreased responsiveness to adenosine, a critical lipolytic inhibitor (Bauman and Vernon, 1993). Thus, increased phosphorylation of HSL may not be necessary for GH to elicit its lipolytic effect. The degree of FR used in this study was chosen to mimic the level of energy insufficiency typical of the first week of lactation, and was expected to stimulate PKA-mediated lipolysis. Our results demonstrate that even though lipolysis is stimulated by energy insufficiency in the transition period and with FR in mid lactation, the physiological context in which energy insufficiency occurs has an effect on the mechanism by which lipolysis is regulated. In particular, our data indicate the classic mechanism of lipolytic stimulation by $\beta$-adrenergic receptor activation and PKA phosphorylation does not have a primary role in the regulation of lipolysis following FR and GH administration in midlactation cows.

Regulation of lipolysis by HSL can also be achieved through phosphorylation of HSL by kinases other than PKA. In 3T3-L1 as well as rat adipocytes, phosphoryla- 
tion of $\mathrm{HSL}_{\text {Ser565 }}$ is mediated by AMPK (Garton et al., 1989; Chaves et al., 2011). This phosphorylation does not affect the activity of HSL per se, but may prevent subsequent phosphorylation of $\mathrm{HSL}_{\mathrm{Ser} 563}$ by PKA (Anthony et al., 2009). Activation of AMPK as observed in mice is associated with the depletion of energy reserves (Gauthier et al., 2008), which is expected with FR and $\mathrm{GH}$ treatment. However, we found that FR and GH elicited a significant decrease in $\mathrm{HSL}_{\text {Ser565, }}$, which may be consistent with a decline in AMPK activation. Activation of AMPK has also been associated with increased expression of ATGL in rat adipocytes (Gaidhu et al., 2010). Thus, our results showing decreased ATGL and HSL $_{\text {Ser565 }}$ following both FR and GH treatments are consistent with an expected decrease in activation of AMPK in these models. Phosphorylation of AMPK has been studied in transition cows, where its activation increased with the onset of lactation (Locher et al., 2012). However, further research is warranted to fully understand the complex interactions among AMPK, ATGL, HSL, and lipolysis throughout lactation.

\section{CONCLUSIONS}

Adaptation to negative energy balance is particularly critical because its severity and duration often translate to declines in reproduction and fertility (Patton et al., 2006; Wathes et al., 2007; Fenwick et al., 2008), as well as increased incidence of health problems (Leslie et al., 2000; Kadokawa and Martin, 2006). The lipolytic response in dairy cows is affected by many physiologic and metabolic states, and is regulated by multiple mechanisms. Importantly, stimulation of lipolysis by PKA phosphorylation of HSL and PLIN are likely critical during early lactation, but less important in response to other lipolytic stimuli later in lactation. The significant downregulation of total PLIN abundance in response to FR and GH administration suggest the barrier effect of PLIN may have a significant effect on lipolysis under certain physiological conditions. Finally, the unexpected decrease in ATGL abundance across all models of energy insufficiency may suggest a unique mechanism for regulation of lipolysis in lactating dairy cows. Our findings demonstrate that lipolysis is regulated by multiple mechanisms, and this must be taken into account when evaluating strategies to manipulate energy utilization and partitioning in lactating cows.

\section{ACKNOWLEDGMENTS}

This project was supported by National Research Initiative Competitive Grant No. 2009-35206-05222 from the USDA Cooperative State Research, Education, and Extension Service (Washington, DC).

\section{REFERENCES}

Anthonsen, M. W., L. Rönnstrand, C. Wernstedt, E. Degerman, and C. Holm. 1998. Identification of novel phosphorylation sites in hormone-sensitive lipase that are phosphorylated in response to isoproterenol and govern activation properties in vitro. J. Biol. Chem. 273:215-221.

Anthony, N. M., M. P. Gaidhu, and R. B. Ceddia. 2009. Regulation of visceral and subcutaneous adipocyte lipolysis by acute AICARinduced AMPK activation. Obesity (Silver Spring) 17:1312-1317. http://dx.doi.org/10.1038/oby.2008.645.

Bauman, D. E., and R. G. Vernon. 1993. Effects of exogenous bovine somatotropin on lactation. Annu. Rev. Nutr. 13:437-461.

Brasaemle, D. L. 2010. Lipolysis control: The plot thickens. Cell Metab. 11:173-174. http://dx.doi.org/10.1016/j.cmet.2010.02.008.

Caimari, A., P. Oliver, and A. Palou. 2008. Impairment of nutritional regulation of adipose triglyceride lipase expression with age. Int. J. Obes. (Lond.) 32:1193-1200. http://dx.doi.org/10.1038/ ijo.2008.69.

Chaves, V. E., D. Frasson, and N. H. Kawashita. 2011. Several agents and pathways regulate lipolysis in adipocytes. Biochimie 93:16311640. http://dx.doi.org/10.1016/j.biochi.2011.05.018.

Contreras, G. A., and L. M. Sordillo. 2011. Lipid mobilization and inflammatory responses during the transition period of dairy cows. Comp. Immunol. Microbiol. Infect. Dis. 34:281-289. http:// dx.doi.org/10.1016/j.cimid.2011.01.004.

Deiuliis, J. A., J. Shin, D. Bae, M. J. Azain, R. Barb, and K. Lee. 2008. Developmental, hormonal, and nutritional regulation of porcine adipose triglyceride lipase (ATGL). Lipids 43:215-225. http://dx.doi.org/10.1007/s11745-007-3146-1.

Duncan, R. E., M. Ahmadian, K. Jaworski, E. Sarkadi-Nagy, and H. S. Sul. 2007. Regulation of lipolysis in adipocytes. Annu. Rev. Nutr. 27:79-101. http://dx.doi.org/10.1146/annurev. nutr.27.061406.093734.

Elkins, D. A., and D. M. Spurlock. 2009. Phosphorylation of perilipin is associated with indicators of lipolysis in Holstein cows. Horm. Metab. Res. 41:736-740. http://dx.doi. org/10.1055/s-0029-1225359.

Fenwick, M. A., S. Llewellyn, R. Fitzpatrick, D. A. Kenny, J. J. Murphy, J. Patton, and D. C. Wathes. 2008. Negative energy balance in dairy cows is associated with specific changes in IGF-binding protein expression in the oviduct. Reproduction 135:63-75. http://dx.doi.org/10.1530/REP-07-0243.

Gaidhu, M. P., N. M. Anthony, P. Patel, T. J. Hawke, and R. B. Ceddia. 2010. Dysregulation of lipolysis and lipid metabolism in visceral and subcutaneous adipocytes by high-fat diet: Role of ATGL, HSL, and AMPK. Am. J. Physiol. Cell Physiol. 298:C961-C971. http://dx.doi.org/10.1152/ajpcell.00547.2009.

Garcia, A., V. Subramanian, A. Sekowski, S. Bhattacharyya, M. W. Love, and D. L. Brasaemle. 2004. The amino and carboxyl termini of perilipin A facilitate the storage of triacylglycerols. J. Biol. Chem. 279:8409-8416. http://dx.doi.org/10.1074/jbc. M311198200.

Garton, A. J., D. G. Campbell, D. Carling, D. G. Hardie, R. J. Colbran, and S. J. Yeaman. 1989. Phosphorylation of bovine hormonesensitive lipase by the AMP-activated protein kinase. A possible antilipolytic mechanism. Eur. J. Biochem. 179:249-254.

Gauthier, M.-S., H. Miyoshi, S. C. Souza, M. Cacicedo, A. K. Saha, A. S. Greenberg, and N. B. Ruderman. 2008. AMP-activated protein kinase is activated as a consequence of lipolysis in the adipocyte: Potential mechanism and physiological relevance. J. Biol. Chem. 283:16514-16524. http://dx.doi.org/10.1074/jbc.M708177200.

Granneman, J. G., H.-P. H. Moore, R. L. Granneman, A. S. Greenberg, M. S. Obin, and Z. Zhu. 2007. Analysis of lipolytic protein trafficking and interactions in adipocytes. J. Biol. Chem. 282:5726-5735. http://dx.doi.org/10.1074/jbc.M610580200.

Greenberg, A. S., J. J. Egan, S. A. Wek, N. B. Garty, E. J. BlanchetteMackie, and C. Londos. 1991. Perilipin, a major hormonally regulated adipocyte-specific phosphoprotein associated with the periphery of lipid storage droplets. J. Biol. Chem. 266:11341-11346. 
Haemmerle, G., R. Zimmermann, M. Hayn, C. Theussl, G. Waeg, E. Wagner, W. Sattler, T. M. Magin, E. F. Wagner, and R. Zechner. 2002. Hormone-sensitive lipase deficiency in mice causes diglyceride accumulation in adipose tissue, muscle, and testis. J. Biol. Chem. 277:4806-4815. http://dx.doi.org/10.1074/jbc.M110355200.

Ji, P., J. S. Osorio, J. K. Drackley, and J. J. Loor. 2012. Overfeeding a moderate energy diet prepartum does not impair bovine subcutaneous adipose tissue insulin signal transduction and induces marked changes in peripartal gene network expression. J. Dairy Sci. 95:4333-4351. http://dx.doi.org/10.3168/jds.2011-5079.

Jocken, J. W. E., D. Langin, E. Smit, W. H. M. Saris, C. Valle, G. B. Hul, C. Holm, P. Arner, and E. E. Blaak. 2007. Adipose triglyceride lipase and hormone-sensitive lipase protein expression is decreased in the obese insulin-resistant state. J. Clin. Endocrinol. Metab. 92:2292-2299. http://dx.doi.org/10.1210/jc.2006-1318.

Kadokawa, H., and B. G. Martin. 2006. A new perspective on management of reproduction in dairy cows: The need for detailed metabolic information, an improved selection index and extended lactation. J. Reprod. Dev. 52:161-168.

Kershaw, E. E., J. K. Hamm, L. A. W. Verhagen, O. Peroni, M. Katic, and J. S. Flier. 2006. Adipose triglyceride lipase: Function, regulation by insulin, and comparison with adiponutrin. Diabetes $55: 148-157$.

Kim, J. Y., K. Tillison, J.-H. Lee, D. A. Rearick, and C. M. Smas. 2006. The adipose tissue triglyceride lipase ATGL/PNPLA2 is downregulated by insulin and TNF- $\alpha$ in $3 \mathrm{~T} 3-\mathrm{L} 1$ adipocytes and is a target for transactivation by PPAR $\gamma$. Am. J. Physiol. Endocrinol. Metab. 291:E115-E127. http://dx.doi.org/10.1152/ ajpendo.00317.2005.

Kolditz, C.-I., and D. Langin. 2010. Adipose tissue lipolysis. Curr. Opin. Clin. Nutr. Metab. Care 13:377-381. http://dx.doi. org/10.1097/MCO.0b013e32833bed6a.

Koltes, D. A., and D. M. Spurlock. 2012. Adipose tissue angiopoietinlike protein 4 messenger RNA changes with altered energy balance in lactating Holstein cows. Domest. Anim. Endocrinol. 43:307316. http://dx.doi.org/10.1016/j.domaniend.2012.05.004.

Koltes, D. A., and D. M. Spurlock. 2011. Coordination of lipid dropletassociated proteins during the transition period of Holstein dairy cows. J. Dairy Sci. 94:1839-1848. http://dx.doi.org/10.3168/ jds.2010-3769.

Lampidonis, A. D., E. Rogdakis, G. E. Voutsinas, and D. J. Stravopodis. 2011. The resurgence of hormone-sensitive lipase (HSL) in mammalian lipolysis. Gene 477:1-11. http://dx.doi.org/10.1016/j. gene.2011.01.007.

Lass, A., R. Zimmermann, M. Oberer, and R. Zechner. 2011. Lipolysis - A highly regulated multi-enzyme complex mediates the catabolism of cellular fat stores. Prog. Lipid Res. 50:14-27. http:// dx.doi.org/10.1016/j.plipres.2010.10.004.

Leslie, K. E., T. Duffield, Y. Schukken, and S. LeBlanc. 2000. Influence of negative energy balance on udder health. Pages 25-33 in Natl. Mastitis Counc. Reg. Mtg. Proc., Univ. Guelph, ON, Canada.

Locher, L. F., N. Meyer, E.-M. Weber, J. Rehage, U. Meyer, S. Dänicke, and K. Huber. 2011. Hormone-sensitive lipase protein expression and extent of phosphorylation in subcutaneous and retroperitoneal adipose tissues in the periparturient dairy cow. J. Dairy Sci. 94:4514-4523. http://dx.doi.org/10.3168/jds.2011-4145.

Locher, L. F., J. Rehage, N. Khraim, U. Meyer, S. Dänicke, K. Hansen, and K. Huber. 2012. Lipolysis in early lactation is associated with an increase in phosphorylation of adenosine monophosphate-activated protein kinase (AMPK) $\alpha 1$ in adipose tissue of dairy cows. J. Dairy Sci. 95:2497-2504. http://dx.doi.org/10.3168/jds.20114830.

Lu, X., X. Yang, and J. Liu. 2010. Differential control of ATGL-mediated lipid droplet degradation by CGI-58 and G0S2. Cell Cycle 9:2719-2725. http://dx.doi.org/10.4161/cc.9.14.12181.

Mairal, A., D. Langin, P. Arner, and J. Hoffstedt. 2006. Human adipose triglyceride lipase (PNPLA2) is not regulated by obesity and exhibits low in vitro triglyceride hydrolase activity. Diabetologia 49:1629-1636. http://dx.doi.org/10.1007/s00125-006-0272-x.

Martin, S., S. Okano, C. Kistler, M. A. Fernandez-Rojo, M. M. Hill, and R. G. Parton. 2009. Spatiotemporal regulation of early lipo- lytic signaling in adipocytes. J. Biol. Chem. 284:32097-32107. http://dx.doi.org/10.1074/jbc.M109.002675.

Miyoshi, H., S. C. Souza, H.-H. Zhang, K. J. Strissel, M. A. Christoffolete, J. Kovsan, A. Rudich, F. B. Kraemer, A. C. Bianco, M. S. Obin, and A. S. Greenberg. 2006. Perilipin promotes hormonesensitive lipase-mediated adipocyte lipolysis via phosphorylation-dependent and -independent mechanisms. J. Biol. Chem. 281:15837-15844. http://dx.doi.org/10.1074/jbc.M601097200.

Moore, H.-P. H., R. B. Silver, E. P. Mottillo, D. A. Bernlohr, and J. G. Granneman. 2005. Perilipin targets a novel pool of lipid droplets for lipolytic attack by hormone-sensitive lipase. J. Biol. Chem. 280:43109-43120. http://dx.doi.org/10.1074/jbc.M506336200.

Nielsen, T. S., U. Kampmann, R. R. Nielsen, N. Jessen, L. Orskov, S. B. Pedersen, J. O. Jørgensen, S. Lund, and N. Møller. 2012. Reduced mRNA and protein expression of perilipin A and G0/G1 switch gene 2 (G0S2) in human adipose tissue in poorly controlled type 2 diabetes. J. Clin. Endocrinol. Metab. 97:E1348-E1352. http://dx.doi.org/10.1210/jc.2012-1159.

NRC. 2001. Nutrient Requirements of Dairy Cattle. 7th ed. Natl. Acad. Press, Washington DC.

Patton, J., D. A. Kenny, J. F. Mee, F. P. O'Mara, D. C. Wathes, M. Cook, and J. J. Murphy. 2006. Effect of milking frequency and diet on milk production, energy balance, and reproduction in dairy cows. J. Dairy Sci. 89:1478-1487.

Rydén, M., J. Jocken, V. van Harmelen, A. Dicker, J. Hoffstedt, M. Wirén, L. Blomqvist, A. Mairal, D. Langin, E. Blaak, and P. Arner. 2007. Comparative studies of the role of hormone-sensitive lipase and adipose triglyceride lipase in human fat cell lipolysis. Am. J. Physiol. Endocrinol. Metab. 292:E1847-E1855. http:// dx.doi.org/10.1152/ajpendo.00040.2007.

SAS Institute. 1999. SAS/STAT User's Guide. Version 6.12. SAS Institute Inc., Cary, NC.

Schweiger, M., R. Schreiber, G. Haemmerle, A. Lass, C. Fledelius, P. Jacobsen, H. Tornqvist, R. Zechner, and R. Zimmermann. 2006. Adipose triglyceride lipase and hormone-sensitive lipase are the major enzymes in adipose tissue triacylglycerol catabolism. J. Biol. Chem. 281:40236-40241. http://dx.doi.org/10.1074/jbc. M608048200.

Subramanian, V., A. Rothenberg, C. Gomez, A. W. Cohen, A. Garcia, S. Bhattacharyya, L. Shapiro, G. Dolios, R. Wang, M. P. Lisanti, and D. L. Brasaemle. 2004. Perilipin A mediates the reversible binding of CGI-58 to lipid droplets in 3T3-L1 adipocytes. J. Biol. Chem. 279:42062-42071. http://dx.doi.org/10.1074/jbc. M407462200.

Villena, J. A., B. Viollet, F. Andreelli, A. Kahn, S. Vaulont, and H. S. Sul. 2004. Induced adiposity and adipocyte hypertrophy in mice lacking the AMP-activated protein kinase- $\alpha 2$ subunit. Diabetes 53:2242-2249. http://dx.doi.org/10.2337/diabetes.53.9.2242.

Wang, H., M. Bell, U. Srinivasan, H. Hu, J. Liu, K. Dalen, C. Londos, T. Yamaguchi, M. A. Rizzo, R. Coleman, D. Gong, D. Brasaemle, and C. Sztalryd. 2011. Unique regulation of adipose triglyceride lipase (ATGL) by perilipin 5, a lipid droplet-associated protein. J. Biol. Chem. 286:15707-15715. http://dx.doi.org/10.1074/jbc. M110.207779.

Wathes, D. C., M. Fenwick, Z. Cheng, N. Bourne, S. Llewellyn, D. G. Morris, D. Kenny, J. Murphy, and R. Fitzpatrick. 2007. Influence of negative energy balance on cyclicity and fertility in the high producing dairy cow. Theriogenology 68:S232-S241.

Watt, M. J., A. G. Holmes, S. K. Pinnamaneni, A. P. Garnham, G. R. Steinberg, B. E. Kemp, and M. A. Febbraio. 2006. Regulation of HSL serine phosphorylation in skeletal muscle and adipose tissue. Am. J. Physiol. Endocrinol. Metab. 290:E500-E508. http:// dx.doi.org/10.1152/ajpendo.00361.2005.

Watt, M. J., and G. R. Steinberg. 2008. Regulation and function of triacylglycerol lipases in cellular metabolism. Biochem. J. 414:313325. http://dx.doi.org/10.1042/BJ20080305.

Yamaguchi, T., N. Omatsu, S. Matsushita, and T. Osumi. 2004 CGI-58 interacts with perilipin and is localized to lipid droplets. Possible involvement of CGI-58 mislocalization in Chanarin-Dorfman syndrome. J. Biol. Chem. 279:30490-30497. http://dx.doi. org/10.1074/jbc.M403920200. 
Yang, X., B. L. Heckmann, X. Zhang, C. M. Smas, and J. Liu. 2013. Distinct mechanisms regulate ATGL-mediated adipocyte lipolysis by lipid droplet coat proteins. Mol. Endocrinol. 27:116-126. http://dx.doi.org/10.1210/me.2012-1178.

Zimmermann, R., J. G. Strauss, G. Haemmerle, G. Schoiswohl, R. Birner-Gruenberger, M. Riederer, A. Lass, G. Neuberger, F. Eisen- haber, A. Hermetter, and R. Zechner. 2004. Fat mobilization in adipose tissue is promoted by adipose triglyceride lipase. Science 306:1383-1386. http://dx.doi.org/10.1126/science.1100747. 